\title{
CHARACTERISTICS AND DIFFERENCES OF POLYPHENOL OXIDASE, PEROXIDASE ACTIVITIES AND POLYPHENOL CONTENT IN DIFFERENT POTATO (SOLANUM TUBEROSUM) TUBERS
}

\author{
WANG, L. ${ }^{1 \#-W A N G, ~ W . ~ X . ~}{ }^{3 \#}-$ ZENG, L. ${ }^{4}-$ SUO, H. C. ${ }^{1}-$ LI, C. C. ${ }^{1}-$ SHAN, J. W. ${ }^{1}-$ LIU, J. T. ${ }^{1}-$ \\ LUO, H. M. ${ }^{1}-\mathrm{LI}, \mathrm{X} . \mathrm{B}^{{ }^{1 *}}{ }^{*} \mathrm{XIONG}, \mathrm{X} . \mathrm{Y}^{2,3,4^{*}}$ \\ ${ }^{1}$ Research Institute of Crops, Provincial Key Laboratory of Crops Genetic Improvement, \\ Guangdong Academy of Agricultural Sciences, Guangzhou, Guangdong 510640, China \\ ${ }^{2}$ Agricultural Genomics Institute at Shenzhen, Chinese Academy of Agricultural Sciences, \\ Shenzhen, China \\ ${ }^{3}$ Institute of Vegetables and Flowers, Chinese Academy of Agricultural Sciences/Key \\ Laboratory of Biology and Genetic Improvement of Root and Tuber Crops, Ministry of \\ Agriculture, Beijing 100081, China \\ ${ }^{4}$ College of Horticulture, Hunan Agricultural University, Changsha, Hunan 410128, China \\ ${ }^{\#}$ These authors contributed equally to this work. \\ *Corresponding authors \\ e-mail: lixiaobo1981@163.com; phone: +86-020-8751-1285 \\ e-mail:xiongxingyao@caas.cn; phone: +86-010-8210-9549 \\ (Received $19^{\text {th }}$ Jul 2020; accepted $7^{\text {th }}$ Oct 2020)
}

\begin{abstract}
Potato enzymatic browning is a serious issue during processing. It not only affects the appearance of potato products but also reduces the nutritional value of potato tubers. In the present study, seven different potato cultivars' tubers were evaluated by measuring the browning index (BI) at different times after cutting. Initial PPO and POD activity and total phenol content, which related to enzymatic browning of plant tissues, were also determined. Results showed significant differences in these factors between the different cultivars. There was significant correlation between BI and PPO, POD activities, but no significant correlation with total phenol content. The activities of PPO and POD and the total phenolic content were higher in the epidermis and perimedullary tissues than pith tissues, which is consistent with their phenotypes. Further, qRT-PCR analysis revealed that the PPO genes were induced by wounding and were more highly expressed in browning-susceptible tubers than browning-resistant tubers, suggesting that browning-susceptible cultivars have higher StuPPO gene expression levels than browning-resistant cultivars. In addition, StuPPO1 and StuPPO2 were the most highly expressed PPO genes in both browning-susceptible/resistant cultivar' tubers, indicating that StuPPO1 and StuPPO2 were the major contributors to the increase in PPO activity and the browning degree in potato tubers. This work suggests that the enzymatic browning of potato tubers is positively correlated with PPO and POD activity. StuPPO1 and StuPPO2 were the main genes responsible for enzymatic browning in potato tubers.
\end{abstract}

Keywords: potato, enzymatic browning, polyphenol oxidase, peroxidase, polyphenol content, PPO genes, correlation, browning index

\section{Introduction}

Enzymatic browning universally occurs in fruits and vegetables. It has a negative impact on the color, flavor, taste, nutritional properties, and shelf life of food products. Browning is considered to be one of the main causes of quality loss during post-harvest handling and processing (Stodt et al., 2014), leading to significant economic losses, 
especially in the agricultural product processing industry. It is estimated that up to $50 \%$ of losses for some tropical fruits are due to enzymatic browning (Whitaker, 1995). Clearly, the control and minimization of enzymatic browning is of great importance to agriculture and the horticultural industry.

Browning is a particularly serious issue for potato (Solanum tuberosum L.), which is grown worldwide and is the fourth most important crop in terms of food production after rice, maize, and wheat (FAOSTAT, 2018). It is estimated that enzymatic browning of potato tubers during harvest and storage alone lead to losses of up to $\$ 300$ million annually in the USA and approximately \$26 million in the UK (Shepherd et al., 2015). Potato tubers have a short storage life, and processing tubers to potato flour is the best way to prolong postharvest shelf life. Potato flour can also be conveniently processed into a variety of foods. However, because potato easily browns and anti-browning processes, including heating and the addition of food additives, are required, the cost of processing potato flour is much higher than that of processing flour from wheat and rice (Ali et al., 2016). This has limited the popularity of potato flour on the market. Because of its important influence on the post-processing of agricultural products, there is a need to fully understand the mechanism of enzymatic browning of potato tubers.

Numerous researchers have suggested that polyphenol oxidase (EC1.10.3.1; PPO) and peroxidase (EC 1.11.1.7; POD) are responsible for enzymatic browning (Jiang et al., 2004; Fortea et al., 2009; Escalante-Minakata et al., 2018). Both PPO and POD can take phenolic compounds as the reaction substrate. However, POD catalyzes phenol oxidation only in the presence of hydrogen peroxide. Therefore, PPO was thought to be the main enzyme in enzymatic browning due to the low $\mathrm{H}_{2} \mathrm{O}_{2}$ concentration in fruit and vegetable tissues (Richard-Forget and Gauillard, 1991; Yang et al., 2004). RichardForget and Gauillard (1991) indicated that in the presence of PPO, POD enhanced the phenol degradation and quinone forms. In other words, POD can enhance the occurrence of enzymatic browning.

PPO genes are widely distributed in plants, animals, and microorganisms (Mayer, 2006). In plants, most PPOs are predicted to be localized in plastids (Yoruk and Marshall, 2003) except for PtrPPO13 in poplar (Populus trichocarpa) and aureusidin synthase (AmAS1) in snapdragon (Antirrhinum majus), which are localized in the nucleus (Ono et al., 2006). By contrast, phenolic compounds, which are the substrates of PPOs, accumulate in vacuoles. Therefore, PPOs can act on phenolic compounds only when the cell membranes are broken. In the presence of oxygen, PPOs catalyze the oxidation of phenolic compounds into o-quinones. O-quinones are highly active and can polymerize and/or react with endogenous amino acids and proteins to form complex brown pigments that precipitate on the surface of the wounded tissues, resulting in the loss of quality of fruits and vegetables (Bittner, 2006). Therefore, tissue browning always occurs after cell damage caused by mechanical damage during harvest, transport, processing, or some stress during storage (Li and Thomas, 2014).

PPO genes are usually present in multigene families in most organisms, and the numbers of PPO genes vary significantly among species (Tran et al., 2012). For instance, there are 11 PPO genes in black poplar (Populus trichocarpa), two in rice (Oryza sativa), eight in sorghum (Sorghum bicolor), four in grapevine (Vitis vinifera), and 19 in Salvia miltiorrhiza (Li et al., 2017). In potatoes, five PPO genes, POTP1/POTP2 (M95196/M95197), POT32 (U22921), POT33 (U22922), and POT72 (U22923), have been cloned (Hunt et al., 1993; Thygesen et al., 1995). All five of these PPO genes have tissue- and development-specific expression patterns and are induced 
by biological and abiotic stress. POTP1 and POTP 2 are only expressed in young leaves and flowers and are most highly expressed in flowers (Thygesen et al., 1995; Thipyapong et al., 1995; Chi et al., 2014).

Although a number of studies about the enzymatic browning of potato tubers have been performed, there are few studies on enzymatic browning and the changes of total phenol content in potato tubers after fresh cutting. In the current study, the relationship between PPO, POD, total phenol and enzymatic browning, and its distribution characteristics in potato tuber were studied. A comparison of PPO and POD activity, total phenol content, and PPO gene expression levels between browning-susceptible (BS) and browning-resistant (BR) cultivars was also conducted. Our results will help us to obtain a deeper understanding of the characteristics of enzymatic browning of fresh-cut potato tubers but also have considerable potential in browning-resistant genetic breeding.

\section{Materials and methods}

\section{Plant material and observation of the browning phenotype}

Four browning-susceptible (BS) potato cultivars (Leshu 1 (L1), Dianshu 6 (D6), Zhongshu7 (Z7), and Zhongshu3 (Z3)) and three browning-resistant (BR) potato cultivars (Zhongshu1 (Z1), Zhongshu4 (Z4), and Xingjia2 (X2)) were randomly selected for this study. The potato cultivars were grown in the Baiyun District Experimental Field, Guangdong Province, China and stored at $4{ }^{\circ} \mathrm{C}$ after harvesting. Before treatment, the tubers were kept at room temperature for two days. Tubers of the same size and with no evidence of mechanical wounding were selected as experimental materials, and were washed with tap water to remove soil. Potato tubers were cut transversely (sliced transverse sections) using a sharp stainless-steel knife, and then kept indoors at $25{ }^{\circ} \mathrm{C}$ with $\sim 80 \%$ relative humidity. At different times after cutting, images were taken with a camera and chromatic values $\left(\Delta \mathrm{E}^{*}\right)$ were obtained using a colorimeter (NS810, 3nh, Shenzhen, China). All experiments were repeated and data from each experimental time point was derived from at least three separate samples of tubers. All the perimedullary tissues used for further determination below were $0.2-1 \mathrm{~cm}$ tissues under the tuber epidermis.

\section{Determination of browning index (BI) and browning degree (BD)}

For the manual inspection, $\Delta \mathrm{E}^{*}$ of the browning of potato tubers were measured using a colorimeter (NS810, 3nh, Shenzhen, China) calibrated with a standard white plate. The browning index (BI) values of potato tubers were determined using a colorimeter (NS810, 3nh, Shenzhen, China). The $\Delta \mathrm{E}^{*}$ was recorded at $0 \mathrm{~h}, 1 \mathrm{~h}, 2 \mathrm{~h}, 3 \mathrm{~h}$, $5 \mathrm{~h}, 8 \mathrm{~h}$, and $12 \mathrm{~h}$ after the tubers were cut transversely. In order to avoid errors caused by uneven browning, $\Delta \mathrm{E}^{*}$ was averaged from five randomly selected points on the perimedullary zone of each potato tuber. The relative BI of each potato tuber was calculated as follows:

$$
\mathrm{BI}_{\chi}=\Delta \mathrm{E}_{\chi}^{*}-\Delta \mathrm{E}^{*}{ }_{0}
$$

$\chi=0,1,2,3,5,8,12 \mathrm{~h}$ after cutting.

The determination of browning degree (BD) was carried out as previously described (Chi et al., 2014) with some modifications. Five grams of fresh tissues including 
perimedullary and pith of tubers were homogenized with $30 \mathrm{ml}$ of precooled distilled water in a mortar on ice, then centrifuged at $10,000 \times \mathrm{g}$ for $5 \mathrm{~min}$ at $4{ }^{\circ} \mathrm{C}$. The supernatant was collected and incubated in a $25{ }^{\circ} \mathrm{C}$ water bath for $5 \mathrm{~min}$. The absorbance was measured using an ultraviolet-visible spectrophotometer (UV-1800, Shanghai Spectrum Instruments Co., Ltd., China) at $410 \mathrm{~nm}$. The absorbance value was used as BD value.

\section{PPO and POD activity test}

PPO and POD activities were assayed spectrophotometrically using a method based on that described by Cao et al. (2007) with some modifications. Three grams of fresh tissue from different sections (including epidermis, perimedullary, and pith) of the potato tubers were homogenized with $5.0 \mathrm{ml}$ of $0.1 \mathrm{~mol} \mathrm{~L}^{-1}$ sodium acetate-acetic acid buffer ( $\mathrm{pH} 5.5,1 \mathrm{mM}$ PEG, $4 \%\left(\mathrm{~W} \mathrm{~V}^{-1}\right)$ PVPP, $1 \%\left(\mathrm{~W} \mathrm{~V}^{-1}\right)$ Triton $\left.\mathrm{X}-100\right)$ on ice. The homogenates were then centrifuged at $12,000 \times \mathrm{g}$ for $30 \mathrm{~min}$ at $4{ }^{\circ} \mathrm{C}$. The supernatant was collected for the PPO and POD activity assays.

PPO activity assay: The reaction cuvette contained $4.0 \mathrm{ml} 50 \mathrm{mM}$ sodium acetate-

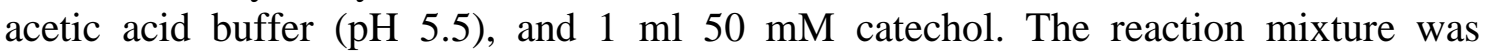
incubated in a $25{ }^{\circ} \mathrm{C}$ water bath for $10 \mathrm{~min}, 100 \mu \mathrm{l}$ enzyme solution was added, and immediately after mixing, the absorbance at $410 \mathrm{~nm}$ was recorded every $10 \mathrm{~s}$ for $2 \mathrm{~min}$.

POD activity assay: The reaction cuvette contained $3.0 \mathrm{ml} 25 \mathrm{mmol} \mathrm{L}^{-1}$ guaiacol, $0.5 \mathrm{ml}$ of the enzyme solution, and $0.2 \mathrm{ml} 5 \mathrm{M}$ hydrogen peroxide. Immediately after mixing, the absorbance at $470 \mathrm{~nm}$ was recorded every $10 \mathrm{~s}$ for $2 \mathrm{~min}$.

An enzyme activity unit (U) was defined as an increase of 0.01 in absorbance per minute per gram fresh weight.

\section{Content of total phenols}

The total phenolic content was measured using the Folin-Ciocalteu procedure (Cen et al., 2016) with some modifications. Two grams of fresh potato tuber tissues were homogenized with $10 \mathrm{ml} 95 \%$ cold alcohol in a precooled mortar. The homogenate was then transferred into a triangular flask and was ultrasonicated $(100 \mathrm{~W})$ in an ultrasonoscope (KQ5200, Kunshan Ultrasonic Instrument Co., Ltd., China) for $2 \mathrm{~h}$. The homogenate was filtered into a $100 \mathrm{ml}$ volumetric flask through four layers of gauze, $95 \%$ alcohol was added to a final volume of $100 \mathrm{ml}$, and the sample was thoroughly mixed. Next, $2 \mathrm{ml}$ filtered homogenate, $2 \mathrm{ml} \mathrm{20 \%} \mathrm{sodium} \mathrm{carbonate,} \mathrm{and} 1.5 \mathrm{ml}$ FolinCiocalteu reagent were added to a $50 \mathrm{ml}$ volumetric flask, and distilled water was added to a final volume of $50 \mathrm{ml}$. After incubation for $30 \mathrm{~min}$ in a $55{ }^{\circ} \mathrm{C}$ water bath, the absorbance of the solution at $765 \mathrm{~nm}$ was measured using an ultraviolet-visible spectrophotometer (UV-1800, Shanghai Spectrum Instruments Co., Ltd., China). A standard curve for gallic acid was used to quantify the total phenolic content, which was expressed as gallic acid equivalents per $\mathrm{g}$ of fresh weight $\left(\mathrm{mg} \mathrm{g}^{-1}\right)$.

\section{Quantification of hydrogen peroxide}

$0.1 \mathrm{~g}$ of the perimedullary tissues of same tubers were used to determine the $\mathrm{H}_{2} \mathrm{O}_{2}$ content at different time $(0,10,20,30 \mathrm{~min})$ after cut-wounding. $\mathrm{H}_{2} \mathrm{O}_{2}$ content was colorimetrically measured using a hydrogen peroxide assay kit (Suzhou Comin Biotechnology Co. Ltd, Suzhou, China) and calculated according to the manufacturer's instructions. 


\section{RNA extraction}

Potato tubers were cut transversely and kept in an incubator set at $25^{\circ} \mathrm{C}$ and $80-90 \%$ humidity. Samples were obtained after 0 h, 1 h, 2 h, 4 h, 8 h, 12 h, and 24 h. All samples were immediately frozen in liquid nitrogen and stored at $-80{ }^{\circ} \mathrm{C}$ for subsequent analysis. Total RNA was extracted using the TiangenRNA extraction kit (Tiangen Biotech Co. Ltd, Beijing, China) according to the manufacturer's instructions and digested with RNase-free DNase I. The concentration of RNA was determined using a NanoDrop UV-visible spectrophotometer (Thermo Fisher Scientific, Waltham, MA, USA), and RNA integrity was evaluated by $1 \%$ agarose gel electrophoresis. First-strand cDNA was synthesized from $1 \mu \mathrm{g}$ RNA using the Tiangen trans kit (Tiangen Biotech Co. Ltd, Beijing, China) following the manufacturer's protocol and stored at $-20{ }^{\circ} \mathrm{C}$ for real-time quantitative PCR (qRT-PCR).

\section{qRT-PCR}

qRT-PCR analysis was performed with first strand cDNA template and Taq DNA polymerase (TaKaRa, Dalian, China) using gene-specific primers (Table 1) (Wang et al., 2019). SYBR Premix Ex Taq ${ }^{\mathrm{TM}}$ II (TaKaRa, Dalian, China) and the Bio-Rad CFX96TM qRT-PCR detection system (Bio-Rad, Hercules, CA, USA) were used according to the manufacturers' instructions. The PCR program was as follows: $30 \mathrm{~s}$ at $95^{\circ} \mathrm{C}$, followed by 40 cycles of $95^{\circ} \mathrm{C}$ for $5 \mathrm{~s}$ and $60{ }^{\circ} \mathrm{C}$ for $30 \mathrm{~s}$. Melting curve analysis was done after the PCR program was complete $\left(65{ }^{\circ} \mathrm{C}\right.$ to $95{ }^{\circ} \mathrm{C}$, at increments of $0.5^{\circ} \mathrm{C}$ ). EFl $\alpha$ (Gene Bank accession AB061263), a housekeeping gene, was used as the internal control (Nicot et al., 2000). The $2^{-\Delta \Delta \mathrm{Ct}}$ method was used to analyze relative mRNA abundance. The expression assay was repeated three times, and each assay was performed with three independent technical replicates. The primers for qRT-PCR analysis were designed using Primer 5 (Lalitha, 2000).

Table 1. The primer sequences of $q R T-P C R$ used in this study

\begin{tabular}{|c|c|c|c|c|c|c|c|}
\hline Transcript name & $\begin{array}{l}\text { Gene } \\
\text { name }\end{array}$ & $\begin{array}{c}\text { Genomic } \\
\text { sequence length }\end{array}$ & $\begin{array}{c}\text { Primer } \\
\text { name }\end{array}$ & Primer sequence (5' - 3') & \begin{tabular}{|c|} 
Length \\
(bp)
\end{tabular} & $\begin{array}{c}\text { GC } \\
\%\end{array}$ & $\begin{array}{l}\text { Tm } \\
\left({ }^{\circ} \mathrm{C}\right)\end{array}$ \\
\hline \multirow{2}{*}{ PGSC0003DMT400076054 } & \multirow{2}{*}{ StuPPO1 } & \multirow{2}{*}{1770} & T054F & TCCGTCCCAATTCTTCGGTG & \multirow{2}{*}{93} & 55.0 & 60.0 \\
\hline & & & T054R & TGAACCGGGGTATGAGGGAT & & 55.0 & 60.0 \\
\hline \multirow{2}{*}{ PGSC0003DMT400048684 } & \multirow{2}{*}{ StuPPO2 } & \multirow{2}{*}{1797} & T684F & ATATCGCGACTGTTGATTTCC & \multirow{2}{*}{133} & 42.9 & 56.5 \\
\hline & & & $\mathrm{T} 684 \mathrm{R}$ & GTCGCACCTTCAATGGAGATA & & 47.6 & 57.8 \\
\hline \multirow{2}{*}{ PGSC0003DMT400048681 } & \multirow{2}{*}{ StuPPO3 } & \multirow{2}{*}{1671} & T681F & GGGGTACGATTACGCACCAA & \multirow{2}{*}{121} & 55.0 & 60.1 \\
\hline & & & $\mathrm{T} 681 \mathrm{R}$ & CGCAAGTGGGAATACCTCGT & & 55.0 & 60.1 \\
\hline \multirow{2}{*}{ PGSC0003DMT400048685 } & \multirow{2}{*}{ StuPPO4 } & \multirow{2}{*}{1791} & T685F & CCAATGGAAATATTACCTTTCT & \multirow{2}{*}{119} & 32.0 & 59.5 \\
\hline & & & $\mathrm{T} 685 \mathrm{R}$ & CATACTGCAACTGCTACTCTCC & & 50.0 & 52.0 \\
\hline \multirow{4}{*}{ PGSC0003DMT400076055 } & \multirow{2}{*}{ StuPPO6 } & \multirow{2}{*}{1791} & T055F & CTCCTGGTGGTCCAGCAGTT & \multirow{2}{*}{124} & 60.0 & 59.6 \\
\hline & & & $\mathrm{T} 055 \mathrm{R}$ & AGATGAGCAGGGGAACGGA & & 57.9 & 60.0 \\
\hline & \multirow{2}{*}{$\mathrm{EF} 1 \alpha$} & & $\mathrm{EF} 1 \alpha-\mathrm{F}$ & ATTGGAAACGGATATGCTCCA & \multirow{2}{*}{101} & 42.9 & 60.0 \\
\hline & & & EF1 $\alpha-R$ & TCCTTACCTGAACGCCTGTCA & & 52.4 & 64.0 \\
\hline
\end{tabular}

\section{Statistical analysis}

All experiments were repeated at least three times form three or more separate samples of tubers collected from twenty potato plants, and each tuber was measured at least twice. The means and standard deviations were calculated. one-way ANOVA was 
performed to ascertain the significance of difference of the mean, and Tukey's test for multiple comparisons for all experimental tests at 0.05 significant level. The correlation analysis between all individual discriminants associated with enzymatic browning was carried out using Pearson's correlation coefficients. Statistical analysis was performed using IBM SPSS Statistics 25.0 (Armonk, NY: IBM Corp.).

\section{Results}

\section{Browning characteristic of potato tubers at different times after cutting}

Seven potato cultivars including four browning-susceptible (BS) cultivars (L1, D6, $\mathrm{Z3}$, and Z7) and three browning-resistant (BR) cultivars (Z1, Z4, and X2) were selected to understand the browning process of potato tubers. Enzymatic browning was rapidly observed in BS cultivars after cutting and increased with time (Fig. 1a). Changes in browning were most obvious from 0 to $3 \mathrm{~h}$. The D6 tubers were more prone to browning than other BS tubers (L1, Z3, and Z7) because they had obvious browning earlier than the others. Browning was not observed in the BR cultivars (Z1, Z4, and X2) until $8 \mathrm{~h}$ after cutting, and only occurred in the part of the tubers close to the epidermis (Fig. 1a). Consistent with the enzymatic browning phenotype of tubers, the BI of BS tubers significantly increased with time, while the BI of BR tubers did not have apparent changes (Fig. 1b).
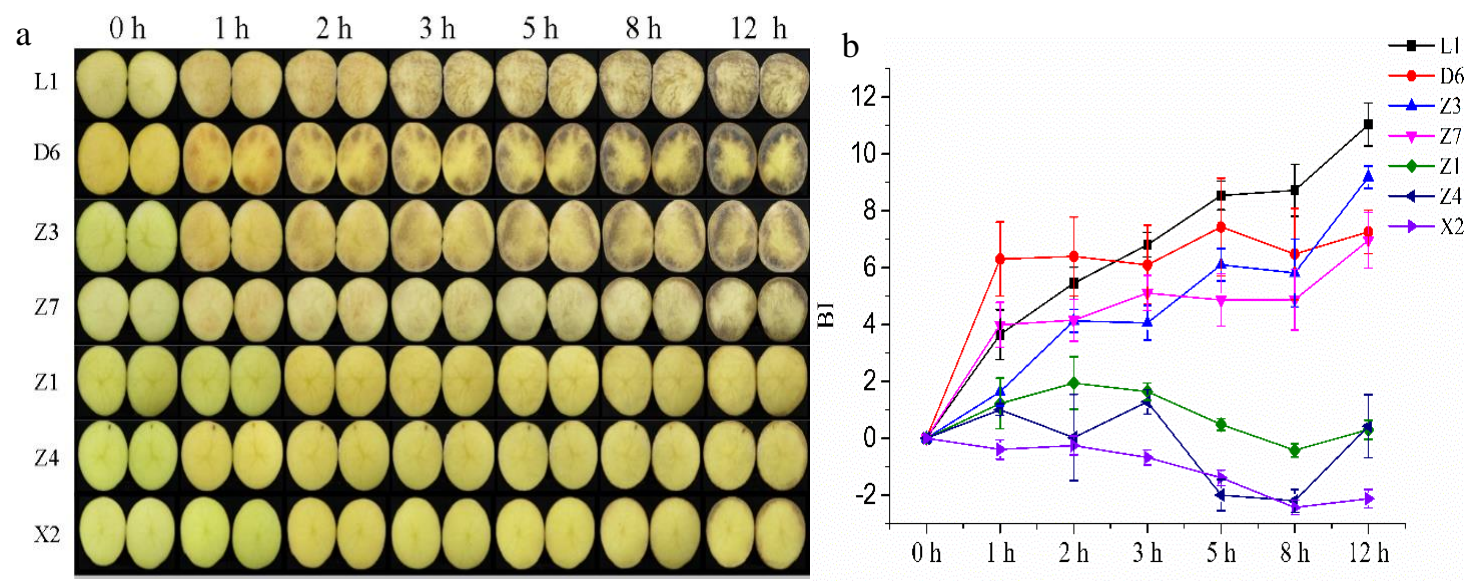

Figure 1. The enzymatic browning process of potato tubers. a, the enzymatic browning of different potato cultivars' tubers after wounding for $0-12 h$; $b$, the change of enzymatic browning index (BI) of different potato cultivars' tubers after wounding for 0-12 h. Values are means \pm s.e. $(n=5)$

\section{Cultivars showing higher browning in fresh-cut potato tubers exhibited higher PPO and POD activity}

The PPO and POD activity and total phenol content had significant differences between different cultivars, especially between BS and BR cultivars (Table 2). The BS tubers had significantly higher PPO and POD activity than BR tubers $(\mathrm{P}<0.05)$ except the POD activity between $\mathrm{Z} 3$ and $\mathrm{X} 2$ tubers, while there were no significant differences in total phenol content. The PPO and POD activity in BS tubers were 10.5-15.65 U and 15.74-37.6 U, respectively; and 5.77-9.68 U and 5.68-11.91 U in BR tubers. L1 had the 
highest PPO activity; D6 tubers had the highest POD and total phenol content; and X2 had the lowest PPO and POD activity. Though D6 tubers have lower PPO activity compared to other BS tubers, they had earlier browning than others, which may be due to D6 having the highest POD activity and total phenol content. In addition, though Z7 tubers had the lowest total phenol content, they browned easily, which might due to Z7 having higher PPO and POD activity. In contrast, though X2 (a BR cultivar) had higher total phenol content, it had the lowest PPO and POD activity. Those results suggested that higher PPO and POD activity were major contributors to a higher degree of enzymatic browning.

Table 2. The BI, PPO and POD activity, and total phenol content of potato varieties. Values are means \pm s.e. $(n=3)$

\begin{tabular}{c|c|c|c|c|c}
\hline & Cultivar & BI & PPO activity (U) & POD activity (U) & $\begin{array}{c}\text { Total phenol } \\
\text { content }\left(\mathbf{m g ~ g}^{-1}\right)\end{array}$ \\
\hline \multirow{3}{*}{$\mathrm{BS}$} & $\mathrm{L} 1$ & $7.00 \pm 0.53 \mathrm{a}$ & $15.65 \pm 2.59 \mathrm{~b}$ & $16.82 \pm 1.45 \mathrm{c}$ & $0.87 \pm 0.17 \mathrm{~cd}$ \\
& $\mathrm{D} 6$ & $6.54 \pm 0.31 \mathrm{ab}$ & $10.50 \pm 0.45 \mathrm{c}$ & $37.60 \pm 4.36 \mathrm{a}$ & $1.21 \pm 0.09 \mathrm{a}$ \\
& $\mathrm{Z} 7$ & $5.64 \pm 0.96 \mathrm{~b}$ & $15.63 \pm 0.99 \mathrm{a}$ & $25.18 \pm 8.82 \mathrm{~b}$ & $0.68 \pm 0.07 \mathrm{~d}$ \\
& $\mathrm{Z} 3$ & $4.391 \pm 0.28 \mathrm{c}$ & $12.73 \pm 0.88 \mathrm{~b}$ & $15.74 \pm 4.31 \mathrm{~cd}$ & $1.12 \pm 0.09 \mathrm{ab}$ \\
\hline \multirow{3}{*}{$\mathrm{BR}$} & $\mathrm{X} 2$ & $-1.24 \pm 0.11 \mathrm{e}$ & $5.77 \pm 0.25 \mathrm{~d}$ & $11.91 \pm 0.66 \mathrm{~cd}$ & $0.90 \pm 0.05 \mathrm{~cd}$ \\
& $\mathrm{Z} 1$ & $1.59 \pm 0.08 \mathrm{~d}$ & $9.68 \pm 0.52 \mathrm{c}$ & $8.87 \pm 1.19 \mathrm{de}$ & $0.97 \pm 0.11 \mathrm{bc}$ \\
& $\mathrm{Z} 4$ & $1.26 \pm 0.04 \mathrm{~d}$ & $6.22 \pm 1.03 \mathrm{~d}$ & $5.68 \pm 0.44 \mathrm{e}$ & $0.76 \pm 0.06 \mathrm{~cd}$ \\
\hline
\end{tabular}

Different letters indicate significant difference between varieties test at $\mathrm{P}<0.05$. BS, browningsusceptible cultivars; BR, browning-resistant cultivars

The correlation analysis also showed that there was a positive correlation between $\mathrm{BI}_{3}$ with PPO and POD activity, the correlation coefficients were 0.79 and 0.675 , respectively. In addition, the cultivars with higher PPO activity also had higher POD activity, the correlation coefficient was 0.528 (Table 3).

Table 3. The correlation analysis between BI, PPO, POD activity, and total phenol content

\begin{tabular}{c|c|c|c|c}
\hline & $\mathbf{B I}_{3}$ & PPO & POD & Total phenol content \\
\hline $\mathrm{BI}_{3}$ & 1 & & & \\
PPO & $0.790^{* *}$ & 1 & & \\
POD & $0.675^{* *}$ & $0.528^{*}$ & 1 & \\
Total phenol content & 0.170 & -0.004 & 0.248 & 1 \\
\hline
\end{tabular}

*Indicates significance at the 0.05 level; ** indicates significance at the 0.01 level

\section{PPO and POD activity and total phenol content in different sections of potato tubers}

During the browning of potato tubers, the perimedullary zones of tubers always have a higher degree of enzymatic browning than pith zones (Fig. 1a). The BS cultivar Z3 and the BR cultivar X2 were used to study this further. BD was recorded as browning value. Consistent with the lower browning phenotype of pith tissues, the BD values of the pith tissues of both cultivars were all lower than those of the perimedullary tissues. In addition, the BD values of both perimedullary and pith tissues of $\mathrm{Z} 3$ were all 


$$
-8178-
$$

obviously higher than those of X2 (Fig. 2), which is consistent with the more pronounced browning phenotype of $\mathrm{Z3}$.

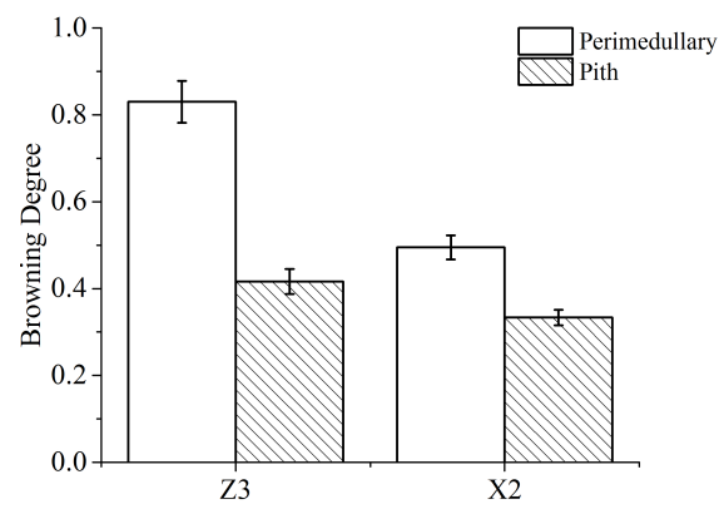

Figure 2. The browning degree $(B D)$ of perimedullary and pith tissues of potato tubers. Z3 and $X 2$ are browning-susceptible $(B S)$ and browning-resistant $(B R)$ potato cultivars, respectively. Values are means \pm s.e. $(n=3)$

Furthermore, the PPO and POD activity and the total phenol content in different sections of potato tubers were investigated (Fig. 3). As shown in Figure 3b, the PPO activity in the epidermis tissues of both cultivars was obviously higher than that in the perimedullary and pith tissues; PPO activity in the epidermis was $1.5-4.7$ and 3.7 13.8 times higher than in the perimedullary and pith tissues, respectively. The pith tissues of tubers had the lowest PPO activity. Similar differences in POD activity between the three different sections were also observed; the activities were $12.5-29.9$ and 26.3 - 42.7 times higher in epidermis tissues than in the perimedullary and pith tissues, respectively. In the Z3 tubers, there was a significant difference in POD activity between the perimedullary and pith tissues; while in X2 tubers, POD activity had no significant difference in between the perimedullary and pith tissues (Fig. 3c). In both cultivars, the epidermis tissues also had the highest total phenol content (Fig. 3d). There was no significant difference in the phenol content between the perimedullary and pith tissues in X2 tubers.

These results indicated that the potato tuber epidermis had the highest levels of PPO and POD activity and polyphenol content, while the pith tissues had the lowest. In browning cultivars, PPO and POD activity and total phenol content in three different parts of tubers were significantly different; in the non-browning cultivars, there were no significant differences in POD activity and total phenol content, but there were significant differences in PPO activity. The epidermis tissue of the BR cultivar X2 had higher PPO and POD activity than BS cultivar Z3, which suggests that the PPO and POD activity in epidermis tissues are not associated with the browning of potato tubers.

\section{Determination of PPO and POD activity and total phenol content at different times in fresh-cut potato tubers}

In order to understand the changes of PPO, POD and total phenol content in potato tubers after cut-wounding, and the difference between susceptible- and resistant-browning tubers, we randomly selected a susceptible-browning cultivar Z3 and a resistant-browning cultivar X2 for further study. Changes of PPO and POD activity and total phenol content 
in $\mathrm{Z} 3$ and $\mathrm{X} 2$ tubers at different times after potato cutting were determined. Overall, the magnitude of the variation of PPO and POD activity of Z3 were large compared to X2, and the magnitude of the variation of perimedullary tissues were small compared to pith tissues (Fig. 4). In Z3 tubers, the PPO activities of perimedullary tissues were high at $0 \mathrm{~h}$ after cutting, fluctuated until reaching a minimum at $12 \mathrm{~h}$, and increased thereafter; the PPO activities of pith tissues started low and gradually increased until $20 \mathrm{~h}$ after cutting (Fig. 4a). In X2 tubers, the PPO activity of both perimedullary and pith tissues exhibited a similar trend with pith tissues of Z3 (Fig. 4b).
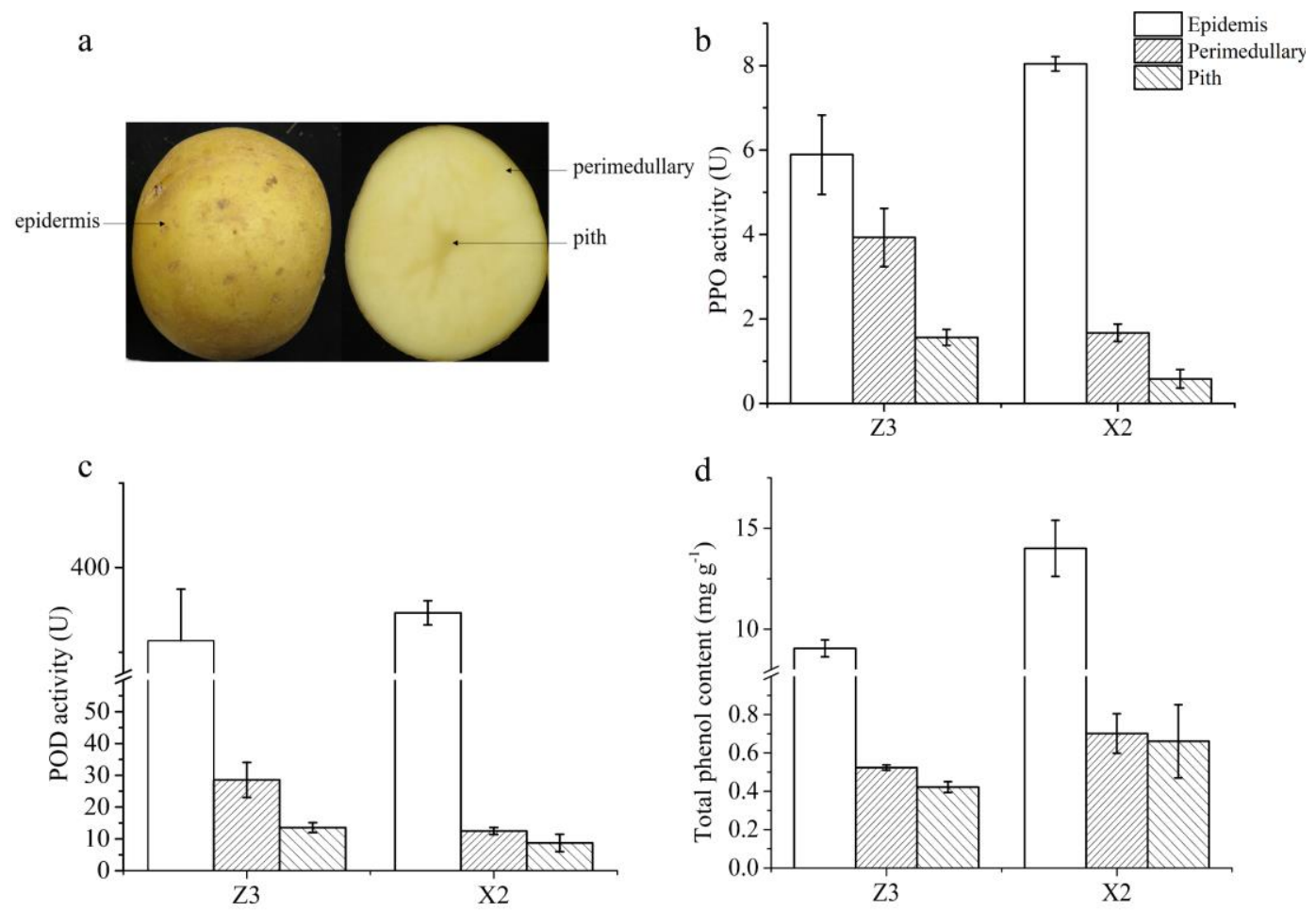

Figure 3. The diagram of potato tubers' structure (a) and PPO activity (b), POD activity (c), total phenol content $(d)$ in epidermis, perimedullary and pith tissue of potato tubers. Z3 and X2 are $B S$ and BR potato varieties, respectively. Values are means \pm s.e. $(n=3)$

The POD activity in perimedullary or pith tissues of Z3 and X2 had similar trends. In perimedullary tissues of $\mathrm{Z} 3$ and $\mathrm{X} 2$, the POD activity did not exhibit a significant increase until $12 \mathrm{~h}$ or $16 \mathrm{~h}$ after cutting, and then sharply increased to its maximum at $20 \mathrm{~h}$ after cutting (Fig. $4 c$ and $d$ ).

The total phenol content in perimedullary tissues of Z3 gradually declined until $2 \mathrm{~h}$ after cutting, then rapidly increased and exhibited the highest level at $4 \mathrm{~h}$. The total phenol content in pith tissues of Z3 and perimedullary and pith tissues of X2 exhibited similar trends. On the contrary, the total phenol content in these tissues increased until $1 \mathrm{~h}$ or $2 \mathrm{~h}$ after cutting, declined until reaching a minimum at $3 \mathrm{~h}$ or $8 \mathrm{~h}$, and increased gradually thereafter (Fig. $4 e$ and $f$ ).

In general, those parameters exhibited similar trends in pith tissues of $\mathrm{Z} 3$ tubers and both perimedullary and pith tissues of X2 tubers. The perimedullary and pith tissues of X2 tubers and the pith tissues of $\mathrm{Z} 3$ tubers do not brown easily compared to the perimedullary tissues 
of Z3 tubers. Those results suggested that the changes of PPO and POD activity and total phenol content are different in BS tissues and BR tissues after cutting.
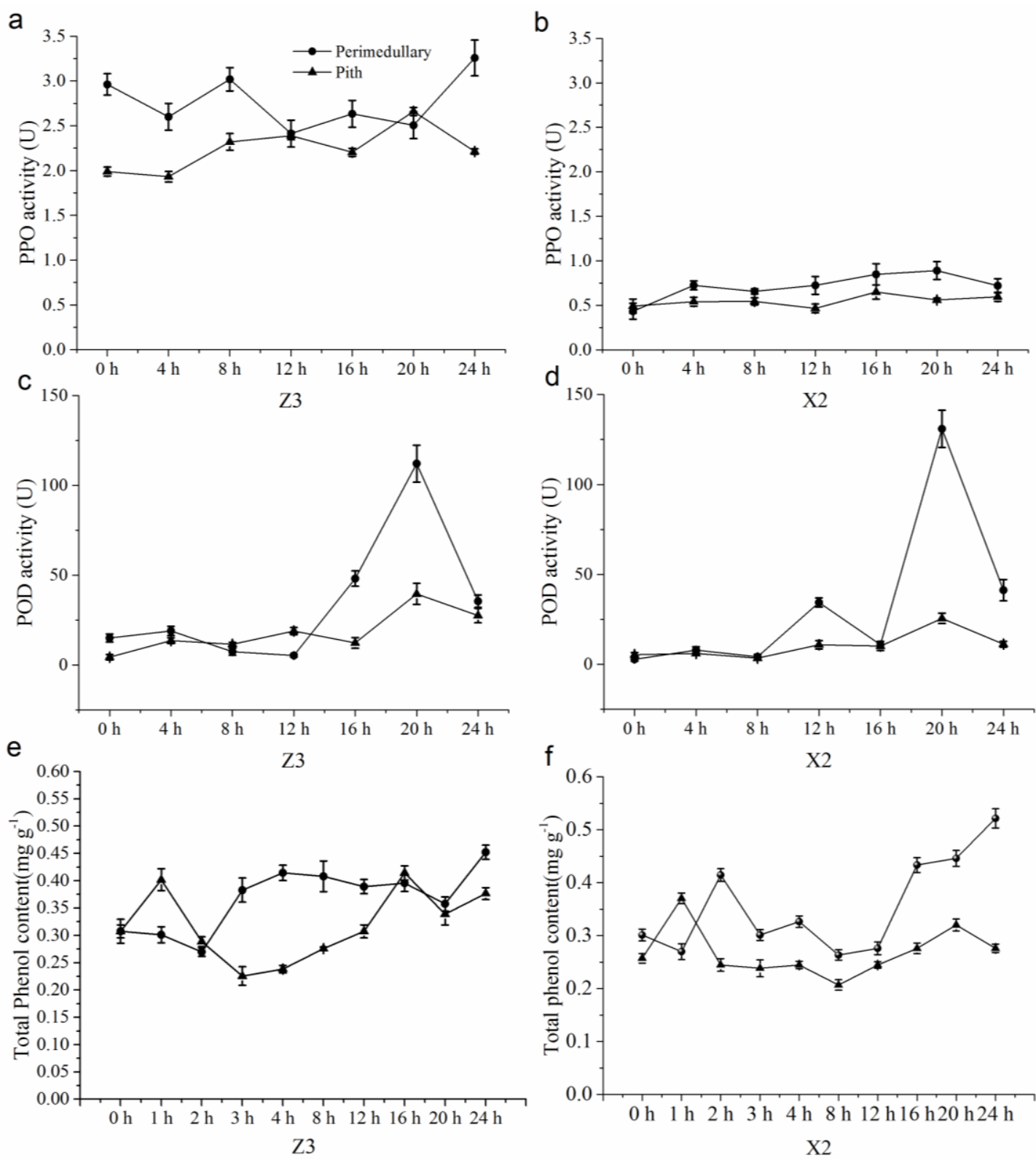

Figure 4. The changes in $P P O, P O D$ activity and total phenol content of potato tubers at different times after wounding. Z3 and X2 are BS and BR potato cultivars, respectively. $a$ and $b$, $P P O$ activity change of $Z 3$ and $X 2$ tubers after wounding, respectively; $c$ and $d, P O D$ activity change of Z3 and X2 after wounding, respectively; $e$ and $f$, the total phenol content change of $Z 3$ and $X 2$ after wounding, respectively. Values are means \pm s.e. $(n=3)$

\section{The production of $\mathrm{H}_{2} \mathrm{O}_{2}$ in potato tubers induced by wounding}

The $\mathrm{H}_{2} \mathrm{O}_{2}$ content in the perimedullary tissues of $\mathrm{Z} 3$ and $\mathrm{X} 2$ tubers were tested. Results showed that the highest content of $\mathrm{H}_{2} \mathrm{O}_{2}$ in potato tubers occur at 20 min after wounding (Fig. 5), which indicated that the production of $\mathrm{H}_{2} \mathrm{O}_{2}$ is induced by cutwounding. 


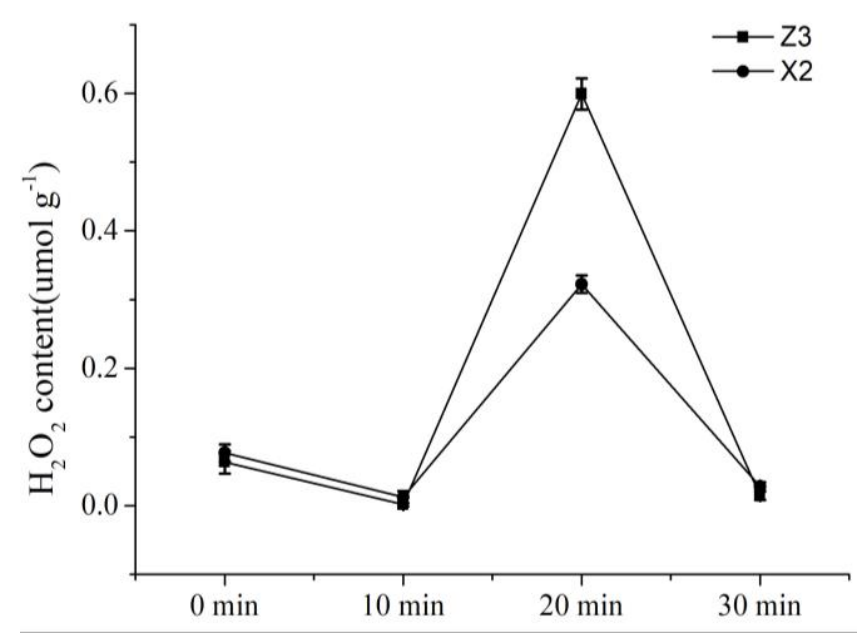

Figure 5. The production of $\mathrm{H}_{2} \mathrm{O}_{2}$ in potato tubers after wounding. $\mathrm{Z} 3$ and $X 2$ are $\mathrm{BS}$ and $\mathrm{BR}$ potato cultivars, respectively. Values are means \pm s.e. $(n=3)$

\section{StuPPO genes and expression profiles in wounded potato tubers}

qRT-PCR was performed to determine the expression patterns of the four StuPPO genes, StuPPO1-StuPPO4, at different times after cutting. As shown in Figure 6, all four StuPPO genes expressed in potato tubers were up-regulated after cutting, and the highest level of expression was observed $12 \mathrm{~h}$ after cutting in Z3 tubers and $24 \mathrm{~h}$ in X2 tubers. Overall, the expression levels of all four StuPPO genes were higher in cultivar Z3 than in X2.
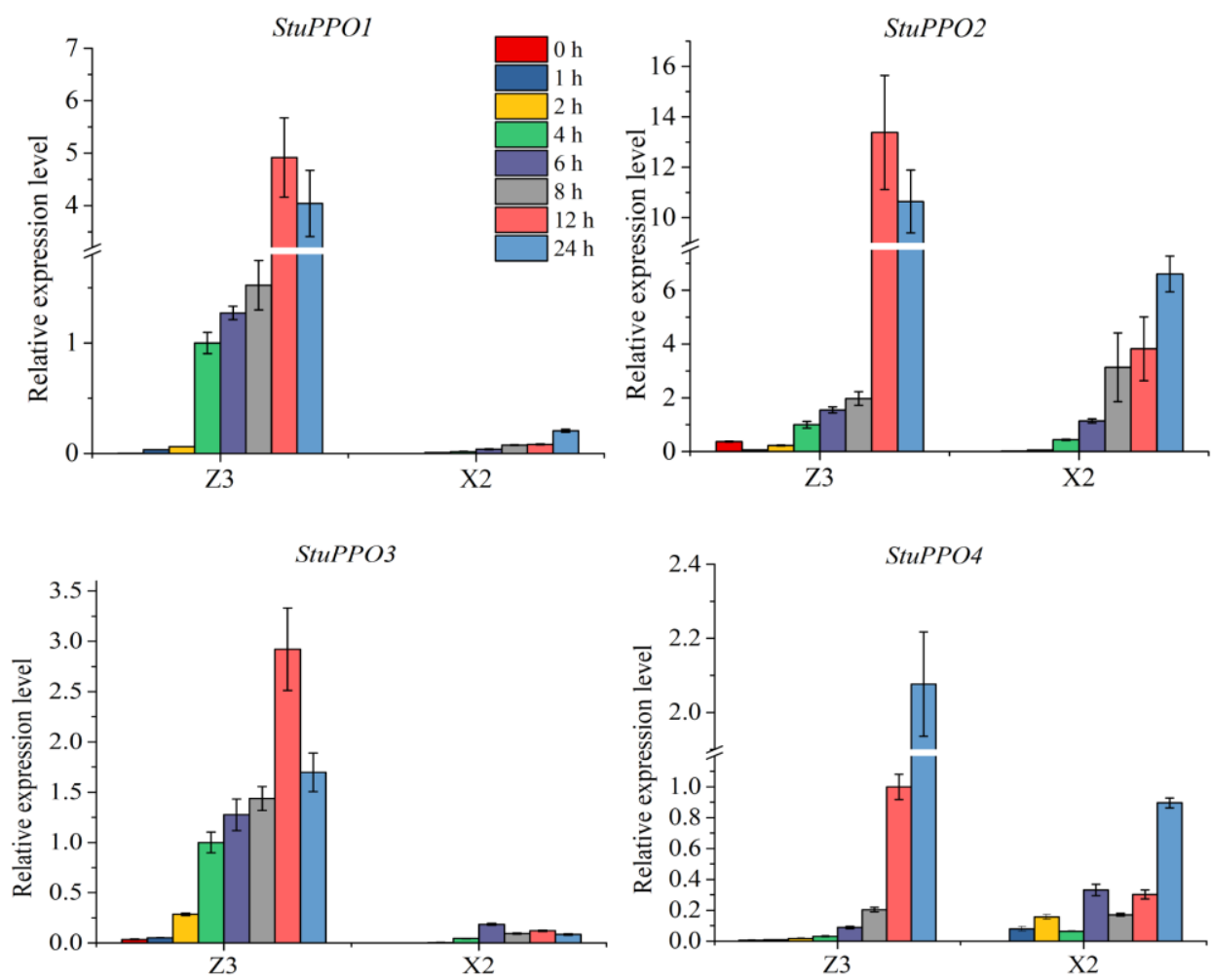

Figure 6. The relative expression levels of five StuPPO genes in potato tubers at different times after wounding. Z3 and X2 are BS and BR potato cultivars, respectively. Values are means \pm s.e. $(n=3)$ 
In addition, the results also showed that the expression level of StuPPO1 in $\mathrm{Z3}$ tubers, and StuPPO1 and StuPPO2 in X2 tubers were much higher than the other StuPPO genes (Fig. 7), which indicated that StuPPO1 and StuPPO2 were more responsible for the enzymatic browning of Z3 and X2 tubers.
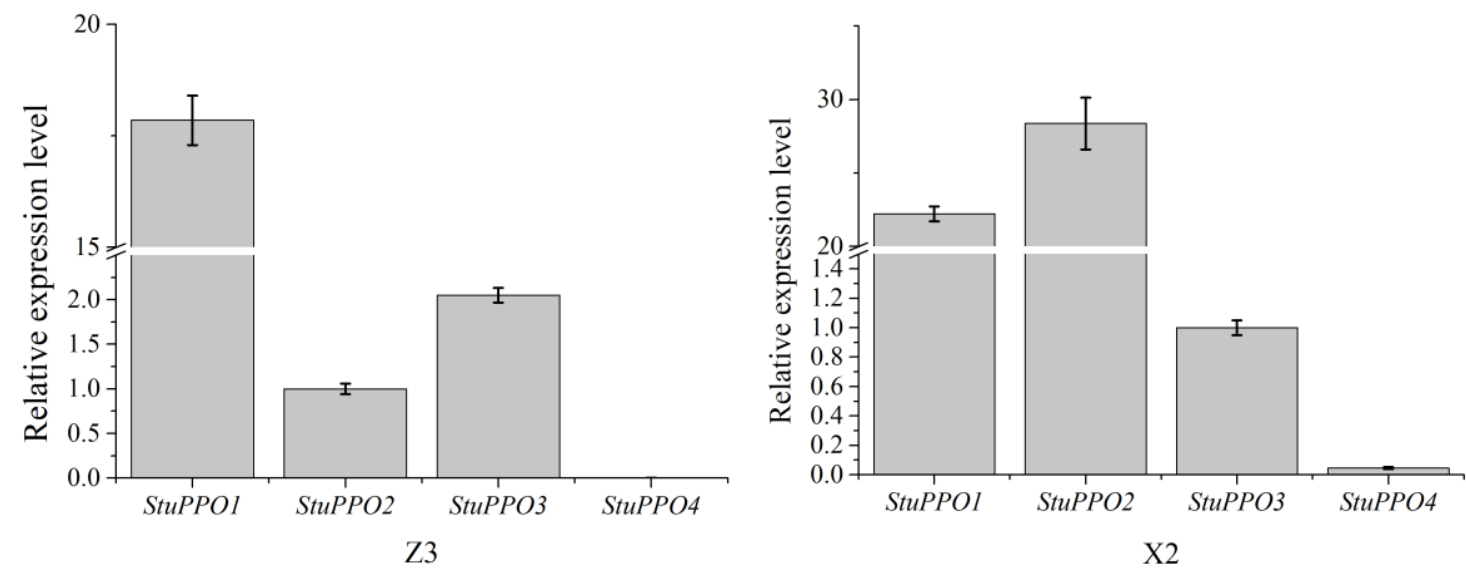

Figure 7. The expression of StuPPO gene in the potato tubers after wounding for $12 \mathrm{~h} . \mathrm{Z3}$ and $X 2$ are $B S$ and BR potato cultivars, respectively. Values are means \pm s.e. $(n=3)$

\section{Discussion}

In this study, seven potato cultivars, including four BS and three BR cultivars, were chosen to reveal contributions to enzymatic browning of potato tubers. The results showed that the BS tubers always have obvious browning after cutting for $1 \mathrm{~h}$, and the browning deepened over time; while the BR cultivars have no significant browning until $8 \mathrm{~h}$ after cutting, and only brown in the tissues close to the epidermis. In general, during the process of tuber browning, changes between 0-3 $\mathrm{h}$ were most obvious after cutting (Fig. 1). The evaluation of enzymatic browning by a colorimeter has been applied to a variety of fruits and vegetables, which can reflect the degree of enzymatic browning more accurately (Cho et al., 2016; Rana et al., 2019). However, in potato tubers, there was a little starch precipitated on the cut surface over time, which results in deviations of $\Delta \mathrm{E}^{*}$ values, especially in BR cultivar tubers, causing negative values of BI (Table 1). Similar results were found by Severini et al. (2003). They also believed that for a comprehensive color evaluation, it is advisable to combine image and colorimeter methods.

In our study, the color gauge evaluation is basically consistent with the photo evaluation (Fig. 1). The results of Severini et al. (2003) showed that the best hue angle values were obtained at a short time of treatment, which is consistent with our results. Therefore, we used the $\mathrm{BI}$ at $3 \mathrm{~h}\left(\mathrm{BI}_{3}\right)$ after cutting to further analyze the correlation between BI with PPO and POD activity and total phenol content of tubers. The results showed that the $\mathrm{BI}_{3}$ of potato tubers was significantly correlated with the PPO and POD activity, and has no significant correlation with total phenol content (Table 2), which consistent with the BS tubers always having higher PPO and POD activity than BR tubers (Table 1). The much higher activity of POD in D6 tubers might the reason for its more obvious browning at $1 \mathrm{~h}$ after cutting though it has lower PPO activity compared to other BS cultivars. Though $\mathrm{H}_{2} \mathrm{O}_{2}$ is required for POD to catalyze phenol compounds, the higher POD activity enhanced the browning occurrence of tubers (Richard-Forget and Gauillard, 1991). PPO was considered works as a promoter for POD activity it 
produces hydrogen peroxide when reacting with phenolic compounds (Tomás-Barberán and Espín, 2001). In our study, cut-wounding induced the production of $\mathrm{H}_{2} \mathrm{O}_{2}$ in potato tubers, which further promote the reaction of POD catalyze the polyphenol. Gong and Tian (2002) reported that the POD purified partially from litchi fruit peel can rapidly oxidize 4-methylcatechol in the presence of $\mathrm{H}_{2} \mathrm{O}_{2}$, supporting the involvement of POD in litchi enzymatic browning. Zhang et al. (2005) showed that POD activity in the pericarp increased consistently with skin browning index during storage of litchi fruit. However, Wen et al. (2020) suggest POD activity might not the key enzyme inducing discoloration of lotus root slices. Therefore, the role of POD in enzymatic browning of different species is different.

In most cultivars, the perimedullary zone of potato tubers was more prone to browning than the pith zone. As expected, PPO and POD activities were higher in the perimedullary tissues than in the pith tissues (Fig. 2). Interestingly, the epidermis tissues of potato tubers had the highest PPO and POD activities, which was also verified by Thygesen et al. (1995). In potato tubers, PPO is localized within amyloplasts (Thygesen et al., 1995). The perimedullary tissues of potato tubers have more amyloplasts (Borzenkova and Borovkova, 2003), which could explain why these tissues have a higher PPO activity than pith tissues. However, why the epidermis tissue has the highest PPO and POD activity requires further research. Obviously, the higher PPO and POD activities in the epidermis did not seem to be correlated with the browning potential of potato tubers. Moreover, the epidermis also had the highest total phenol content, which was consistent with the protective function of phenols against fruit bacterial infection (Ende et al., 2014; Jia et al., 2016). Higher levels of PPO and POD activity and phenol content can promote wound healing and decrease rotting (Yang and Bernards, 2006; Golubenko et al., 2007; Kumar et al., 2010; Shao et al., 2010; Lin et al., 2012). In addition, these findings also indicated that the epidermis of potato tubers can be used as a good source of phenols, which are beneficial to people's health (Albishi et al., 2013). Similarly, Albishi et al. (2013) also found that almost 50\% of phenolic compounds in potato tubers are located in the tuber epidermis and adjoining tissues and the concentration of these compounds decreases towards the center of the tubers.

We further investigated the changes in PPO and POD activity and total phenol in potato tubers after cutting for different times. In our results, the variation trends of those parameters were similar in BR tissues, which include the pith tissues of Z3 tubers and perimedullary and pith tissues of X2 tubers, and were different between BS and BR tissues. In perimedullary tissues of Z3, the PPO activity gradually declined until $16 \mathrm{~h}$ after cutting, and subsequently increased. Due to the consumption of total phenol content after cutting, the initial PPO activity gradually declined and then increased, possibly because latent PPO was converted to its active form when wound stress was applied (Mishra and Gautam, 2016). In BR tissues, the PPO activity exhibited a slight, continuous increase. Unlike PPO, the POD activity did not change significantly during $0-12 \mathrm{~h}$ or $0-16 \mathrm{~h}$ after cutting. The highest POD activity was reached at $20 \mathrm{~h}$ after cutting, which may be the result of gene expression induced by wounding. In the perimedullary tissues of Z3 tubers, the total phenol content gradually declined in early stage after cutting, and subsequently increased due to the production of phenol compounds induced by wounding (Guan et al., 2020). A wound signal originates at the site of injury in lettuce (Lactuca sativa L.) leaf tissues and propagates into adjacent tissue where it induces a number of physiological responses including increased PPO, POD, and phenolic metabolism (Choi et al., 2005; Adams and Brown, 2007; Quarta et al., 2013). 
PPO genes are well known to be induced by stresses such as wounding and pathogen infection (Aziz et al., 2019). As the key enzyme of plant enzymatic browning, the induced expression of PPO genes further promotes the occurrence of tissue enzymatic browning. In our study, four genes expressed in potato tubers were up-regulated by wounding. The highest expression levels of StuPPO genes in Z3 tubers were observed $12 \mathrm{~h}$ after cutting, while in X2 tubers, the highest expression levels were observed $24 \mathrm{~h}$ after cutting. Those results indicate that the expression of StuPPO genes in potato tuber tissues increased more rapidly in the BS cultivars than in the BR cultivars. Consistent with the higher levels of StuPPO gene expression, more browning occurred in a shorter period of time in the BS cultivars than in the BR cultivars. In addition, our results also suggested that StuPPO1 and StuPPO2 were the major genes responsible for browning of potato tubers due to higher expression, which is consistent with the result of Chi et al. (2014).

\section{Conclusions}

In the present study, the PPO and POD activity were higher in BS cultivar tubers than in BR cultivar tubers, which is consistent with their phenotypes. Compared to pith tissues, the perimedullary tissues had higher PPO and POD activity and total phenol content than pith tissues, and the epidermis had the highest. Furthermore, the PPO and POD activity and expression of StuPPO genes were induced by wounding. The expression of StuPPO1 and StuPPO2 were highest in Z3 and X2 tubers. Taken together, our results show that the PPO and POD activity were major contributors in the enzymatic browning of potato tubers. Those results are helpful in understanding the enzymatic browning of fresh-cut potato tubers. In the future, it is necessary to focus on the physiological and molecular mechanisms of the difference in enzyme activity and total phenol content distribution in different parts of potato tuber.

Acknowledgements. We thank Xianzhou Nie of the Potato Research Centre, Agriculture and Agri-Food Canada for constructive comments on an earlier draft of the manuscript. This work was supported by the Guangdong natural science foundation [grant number 2018A030313336], the Science and Technology Planning Project of Guangdong Province [grant number 2017A020208033, 2017B020232002], the Special Fund for Agro-scientific Research in Public Interest of China (201503001), Science Fund opening project of key Laboratory of Crop Germplasm Innovation and Resource Utilization (National Key Laboratory Breeding Base jointly built by provincial and Ministry)(18KFXM03), the Fundamental Research Funds for the Laboratory of Biology and Genetic Improvement of Tuber and Root Crops, Ministry of Agriculture, China (NYBSL201701) and The Guangdong Modern Seed Industry Project (YueCaiNong[2017] \#88).

\section{REFERENCES}

[1] Adams, J. B., Brown, H. M. (2007): Discoloration in raw and processed fruits and vegetables. - Critical Review in Food Science and Nutrition 47: 319-333.

[2] Albishi, T., John, J. A., Al-Khalifa, A. S., Shahidi, F. (2013): Phenolic content and antioxidant activities of selected potato varieties and their processing by-products. Journal of Function Foods 5: 590-600.

[3] Ali, H. M., El-Gizawy, A. M., El-Bassiouny, R. E., Saleh, M. A. (2016): The role of various amino acids in enzymatic browning process in potato tubers, and identifying the browning products. - Food Chemistry 192: 879-885. 
[4] Aziz, E., Batool, R., Akhtar, W., Rehman, S., Gregersen, P. L., Mahmood, T. (2019): Expression analysis of the polyphenol oxidase gene in response to signaling molecules, herbivory and wounding in antisense transgenic tobacco plants. - 3 Biotech 9: 55.

[5] Bittner, S. (2006): When quinones meet amino acids: chemical, physical and biological consequences. - Amino Acids 30: 205.

[6] Borzenkova, R. A., Borovkova, M. P. (2003): Developmental patterns of phytohormone content in the cortex and pith of potato tubers as related to their growth and starch content. - Russian Journal of Plant Physiology 50: 119-124.

[7] Cao, J. K., Jiang, W. B., Zhao, Y. M. (2007): Fruits and Vegetables Postharvest Physiological and Biochemical Guidance. $2^{\text {nd }}$ Ed. - Academic Press Inc, Beijing.

[8] Cen, Z. Y., Shu, J., Deng, X. C., Xie, Y. J. (2016): Study on total phenolic content and correlation between PPO activity and browning of corydalis saxicola bunting callus. Crops 1: 149-153.

[9] Chi, M., Bhagwat, B., Lane, W. D., Tang, G., Su, Y., Sun, R., et al. (2014): Reduced polyphenol oxidase gene expression and enzymatic browning in potato (Solanum tuberosum L.) with artificial microRNAs. - BMC Plant Biology 14: 62.

[10] Cho, J. S., Lee, H. J., Park, J. H., Sung, J. H., Choi, J. Y., Moon, K. D. (2016): Image analysis to evaluate the browning degree of banana (Musa spp.) peel. - Food Chemistry 194: 1028-1033.

[11] Choi, Y. J., Tomás-Barberán, F. A., Saltveit, M. E. (2005): Wound-induced phenolic accumulation and browning in lettuce (Lactuca sativa L.) leaf tissue is reduced by exposure to n-alcohols. - Postharvest Biology and Technology 37: 47-55.

[12] Ende, W. V. D., El-Esawe, S. K. (2014): Sucrose signaling pathways leading to fructan and anthocyanin accumulation: a dual function in abiotic and biotic stress responses? Environmental and Experimental Botany 108: 4-13.

[13] Escalante-Minakata, P., Ibarra-Junquera, V., Ornelas-Paz, J. D. J., García-Ibáñez, V., Virgen-Ortíz, J. J., González-Potes, A., et al. (2018): Comparative study of the banana pulp browning process of 'Giant Dwarf' and FHIA-23 during fruit ripening based on image analysis and the polyphenol oxidase and peroxidase biochemical properties. Biotechnology 8: 30.

[14] FAOSTAT (2018): http://faostat3.fao.org/. - FAO, Rome.

[15] Fortea, M. I., Lópezmiranda, S., Serranomartínez, A., Carreño, J., Núñezdelicado, E. (2009): Kinetic characterisation and thermal inactivation study of polyphenol oxidase and peroxidase from table grape (crimson seedless). - Food Chemistry 113: 1008-1014.

[16] Golubenko, Z., Akhunov, A., Khashimova, N., Beresneva, Y., Mustakimova, E., Ibragimov, F., et al. (2007): Induction of peroxidase as a disease resistance response in resistant (Hibiscus trionum) and susceptible (Althea armeniaca) species in the family malvaceae. - Phytoparasitica 35: 401-413.

[17] Gong, Q. Q., and Tian, S. P. (2002): Partial characterization of soluble peroxidase in pericarp of litchi fruit. - Progress in Biochemistry \& Biophysics 29: 891-896.

[18] Guan, Y., Hu, W., Jiang, A., Xu, Y., Zhao, M., Yu, J., et al. (2020): The effect of cutting style on the biosynthesis of phenolics and cellular antioxidant capacity in wounded broccoli. - Food Research International 137: 109565.

[19] Hunt, M. D., Eannetta, N. T., Yu, H., Newman, S. M., Steffens, J. C. (1993): cDNA cloning and expression of potato polyphenol oxidase. - Plant Molecular Biology 21: 5968.

[20] Jia, H., Zhao, P., Wang, B., Tariq, P., Zhao, F., Zhao, M., et al. (2016): Overexpression of polyphenol oxidase gene in strawberry fruit delays the fungus infection process. - Plant Molecular Biology Report 34: 592-606.

[21] Jiang, Y., Duan, X., Joyce, D., Zhang, Z., Li, J. (2004): Advances in understanding of enzymatic browning in harvested litchi fruit. - Food Chemistry 88: 443-446. 
[22] Kumar, G. N. M., Lulai, E. C., Suttle, J. C., Knowles, N. R. (2010): Age-induced loss of wound-healing ability in potato tubers is partly regulated by ABA. - Planta 232: 14331445.

[23] Lalitha, S. (2000): Primer Premier 5. - The Computer Software Journal for Scient 1: 270272.

[24] Li, Z., Thomas, C. (2014): Quantitative evaluation of mechanical damage to fresh fruits. - Trends in Food Science \& Technology 35: 138-150.

[25] Li, C., Li, D., Li, J., Shao, F., Lu, S. (2017): Characterization of the polyphenol oxidase gene family reveals a novel microRNA involved in post-transcriptional regulation of PPOs in Salvia miltiorrhiza. - Scientific Reports 7: 1-15.

[26] Lin, J. S., Lin, C. C., Lin, H. H., Chen, Y. C., Jeng, S. T. (2012): MicroR828 regulates lignin and $\mathrm{H}_{2} \mathrm{O}_{2}$ accumulation in sweet potato on wounding. - New Phytology 196: $427-$ 440.

[27] Mayer, A. M. (2006): Polyphenol oxidases in plants and fungi: going places? A review. Phytochemistry 67: 2318-2331.

[28] Mishra, B. B., Gautam, S. (2016): Polyphenol oxidases: biochemical and molecular characterization, distribution, role and its control. - Enzyme Engineering 5: 1-9.

[29] Nicot, N., Hausman, J. L., Evers, D. (2000): Housekeeping gene selection for real-time RT-PCR normalization in potato during biotic and abiotic stress. - Journal of Experimental Botany 56: 2907-2914.

[30] Ono, E., Hatayama, M., Isono, Y., Sato, T., Watanabe, R., Yonekura-Sakakibara, K., et al. (2006): Localization of a flavonoid biosynthetic polyphenol oxidase in vacuoles. - The Plant Journal 45: 133-143.

[31] Quarta, A., Mita, G., Durante, M., Arlorio, M., De Paolis, A. (2013): Isolation of a polyphenol oxidase (PPO) cDNA from artichoke and expression analysis in wounded artichoke heads. - Plant Physiology \& Biochemistry 68: 52-60.

[32] Rana, S. S., Pradhan, R. C., Mishra, S. (2019): Image analysis to quantify the browning in fresh cut tender jack fruit slices. - Food Chemistry 278: 185-189.

[33] Richard-Forget, F. C., Gauillard, F. A. (1991): Oxidation of chlorogenic acid, catechins, and 4-methylcatechol in model solutions by combinations of pear (Pyrus communis $\mathrm{Cv}$. Williams) polyphenol oxidase and peroxidase: a possible involvement of peroxidase in enzymatic browning. - Journal of Agriculture \& Food Chemistry 45: 2472-2476.

[34] Severini, C., Baiano, A., Pilli, T. D., Romaniello, R., Derossi, A. (2003): Prevention of enzymatic browning in sliced potatoes by blanching in boiling saline solutions. - LWTFood Science \& Technology 36: 657-665.

[35] Shao, X., Tu, K., Tu, S., Su, J., Zhao, Y. (2010): Effects of heat treatment on wound healing in gala and red fuji apple fruits. - Journal of Agriculture \& Food Chemistry 58: 4303-4309.

[36] Shepherd, L. V. T., Alexander, C. J., Hackett, C. A., McRae, D., Sungurtas, J. A., Verrall, S. R., Morris, et al. (2015): Impacts on the metabolome of down-regulating polyphenol oxidase in potato tubers. - Transgenic Research 24: 447-461.

[37] Stodt, U. W., Blauth, N., Niemann, S., Stark, J., Pawar, V., Jayaraman, S., et al. (2014): Investigation of processes in black Tea manufacture through model fermentation (oxidation) Experiments. - Journal of Agriculture \& Food Chemistry 62: 7854-7861.

[38] Thipyapong, P., Hunt, M. D., Steffens, J. C. (1995): Systemic wound induction of potato (Solanum tuberosum) polyphenol oxidase. - Phytochemistry 40: 673-676.

[39] Thygesen, P. W., Dry, I. B., Robinson, S. P. (1995): Polyphenol oxidase in potato (a multigene family that exhibits differential expression patterns). - Plant Physiology 109: 525-531.

[40] Tomás-Barberán, F. A., Espín, J. C. (2001): Phenolic compounds and related enzymes as determinants of quality in fruits and vegetables. - Journal of the Science of Food \& Agriculture 81: 853-876. 


$$
-8187 \text { - }
$$

[41] Tran, L. T., Taylor, J. S., Constabel, C. P. (2012): The polyphenol oxidase gene family in land plants: lineage-specific duplication and expansion. - BMC genomics 13: 395.

[42] Wang, L., Wang, W. X., Suo, H. C., Hu, X. X., Qin, Y. Z., Li, X. B., et al. (2019): Bioinformatics and expression analysis of polyphenol oxidase gene family in potato. Journal of Hunan Agricultural University (Natural Sciences) 45: 601-610 (in Chinese).

[43] Wen, B., Li, D., Tang, D., Huang, Z., Kedbanglai, P., Ge, Z., et al. (2020): Effects of simultaneous ultrasonic and cysteine treatment on antibrowning and physicochemical quality of fresh-cut lotus roots during cold storage. - Postharvest Biology \& Technology 168: 111294.

[44] Whitaker, J. R. (1995): Recent Advances in Chemistry of Enzymatic Browning. - In: Lee, C. Y., Whitaker, J. R. (eds.) Enzymatic Browning and Its Prevention. American Chemical Society, Washington, DC.

[45] Yang, W. L., Bernards, M. A. (2006): Wound-induced metabolism in potato (Solanum tuberosum) tubers: biosynthesis of aliphatic domain monomers. - Plant Signal \& Behavior 1: 59-66.

[46] Yang, C. P., Nong, Z. R., Jian-Lin, L. U., Lu, L. U., Jian-Shou, X. U., Han, et al. (2004): Banana polyphenol Oxidase: occurrence and change of polyphenol oxidase activity in some banana cultivars during fruit development. - Food Science \& Technology Research 10: 75-78.

[47] Yoruk, R., Marshall, M. R. (2003): Physicochemical properties and function of plant polyphenol oxidase: a review. - Journal Food Biochemistry 27: 361-422.

[48] Zhang, Z., Pang, X., Xue, W. D., Ji, Z., Jiang, Y. (2005): Role of peroxidase in anthocyanin degradation in litchi fruit pericarp. - Food Chemistry 90: 47-52. 